\title{
Histomorphological Study of The Spectrum of Prostatic Lesions in Surgical Biopsy Specimens.
}

\author{
Srikanth. K, N. Gandhi, Mourouguessine Vimal* and Erli Amel Ivan \\ Department of Pathology, Sri Manakula Vinayagar Medical College and Hospital, Puducherry, India.
}

\begin{abstract}
Background: Prostatism is one of the commonest health concerns in geriatric population with significant morbidity and mortality. The incidence of it increases with age. Histopathological evaluation plays a major role in the diagnosis and management of Prostate lesions. Aims and Objectives: To study the spectrum of prostate specimens encountered by the pathologists and to categorize them based on their histomorphological features and to correlate it with the clinical and other laboratory parameters. Material and methods: Hematoxylin and Eosin sections of 100 prostatic biopsies received in the department of Pathology of a tertiary care centre over a period of 18 months were studied. Relevant clinical and laboratory data were collected.

Results: Out of 100 prostatic biopsies studied, 91 were TURP and 9 were core biopsies. Prostatic lesions was common in the age group of $61-70$ years. $75 \%$ of cases were benign with or without prostatitis, $15 \%$ malignant and $10 \%$ cases were pre malignant. $25 \%$ cases were found to have associated prostatitis with the benign and malignant lesions. The most common microscopic feature in benign cases was fibromuscular hyperplasia.

Conclusion: The present study shows that benign lesions are more common than the malignant ones. Among benign lesions, BPH was the most common entity. The most common age group affected was 7 th decade.
\end{abstract}

Keywords: Prostatic Lesions, TURP, Prostatism, Benign Prostatic Hyperplasia, Prostatitis

\section{Introduction}

The incidence of prostatism increases with age beyond $6^{\text {th }}$ decade and is one of the commonest health concerns in geriatric population with significant morbidity and mortality. Clinical examination including Digital rectal examination is a prerequisite to evaluate prostatic lesions. Laboratory investigations including estimation of Prostatic Specific Antigens aid in the diagnosis of prostatic lesions but its clinical significance is complete only when it is supported by histopathological examination. Thus Histopathological evaluation plays a major role in the diagnosis and management of Prostate lesions as both benign and malignant prostatic lesions present with similar clinical presentation. Thus Prostatic specimens have become a significant workload for a pathologist and Trans Urethral Resection Prostate (TURP) specimens and Prostatic biopsies often pose a diagnostic challenge for the practicing pathologists. Thus we aimed to study the spectrum of prostatic specimens received in a tertiary care hospital and categorize the histomorphological features.

Aims and Objectives: To study the spectrum of prostate specimens encountered by the pathologists and to categorize them based on their histomorphological features and to correlate it with the clinical parameters.

\section{Materials and Methods}

The Study was commenced after obtaining Institutional ethics committee clearance and informed consent from the study participants. The study period was 18 months. It was a hospital based cross sectional study which included all the prostatic biopsy specimens including TURP and core biopsies received in the Pathology department. Macroscopic examination of the specimen included total grams \& number of cores in case of needle biopsies. The received specimens were fixed in $10 \%$ formalin, routine haematoxylin and eosin staining was done. The relevant clinical data including age, symptoms like frequency of micturition, urgency, poor stream, hesitancy, acute retention, dysuria and their duration was obtained from biopsy requisitions and case records from Medical records department.

Data was entered in Epi Info version 7.2.2.6 and analysed using software, Statistical Package for Social Sciences (SPSS) version 24.0. Description of categorical variables like age category, clinical features, nature of specimen was done in frequency and percentage.

Association between age categories, clinical features with microscopic details of diagnosis was done using Chisquare test. All tests were two tailed and $p$ value $<0.05$ was considered statistically significant. 


\section{Results}

A total of 100 biopsies were received in the department of pathology during the study period. Among 100 biopsies, 91 were TURP and 9 were needle core biopsies. Majority (82.4\%) of TURP biopsies were found to be benign, $10.9 \%$ were pre malignant and $6.6 \%$ malignant. All the 9 needle core biopsies turned out to be malignant.

Regarding the histopathological diagnosis, majority (53\%) were diagnosed as benign prostatic hyperplasia (BPH), $21 \%$ cases were diagnosed as $\mathrm{BPH}$ with prostatitis, $7 \%$ were $\mathrm{BPH}$ with PIN, 2\% were $\mathrm{BPH}$ with prostatitis and PIN, 1\% was BPH with granulomatous prostatitis, $1 \%$ was PIN with Prostatic small acinar cell proliferation and 15\% cases were diagnosed as Adenocarcinoma (Table 1) $25 \%$ cases were found to have associated prostatitis with the benign and malignant lesions.

The minimum age in this study was 52 years and the maximum was 90 years. The commonest age group in our study population were in the age group of $61-70$ years $(47 \%)$ at the time of presentation. The next common age group affected was 71-80 years (34\%). The incidence of pre malignant lesions was common in the $8^{\text {th }}$ decade $(70.6 \%)$. Among patients with BPH Minimum age was 52 years and the maximum was 90 years. In case of patients with malignancy, minimum age was 59 years and maximum was 75 years. In our study, the average age of presentation of $\mathrm{BPH}$ and adenocarcinoma was 68.7 and 67.3 respectively.

In all cases, acute retention was the most common clinical presentation seen both in benign and malignant lesions. All patients in the premalignant and malignant spectrum had the symptoms of frequency. The other significant clinical presentation were urgency and hesitancy. (Table.2) In benign cases, the stroma showed fibrous hyperplasia and muscular hyperplasia in all cases. Most of the glands showed corpora amylacea (93\%) and papillary infoldings $(92 \%)$. The other significant findings noted were Ectatic blood vessels $(76 \%)$, stromal fragments with atrophic glands $(69.3 \%)$, nodular hyperplasia $(68 \%)$ and Basal cell hyperplasia (64\%) (Table 3)

Table 1: Histopathologic diagnosis of the study cases.

\begin{tabular}{|c|c|}
\hline Histologic diagnosis & Frequency and \% \\
\hline \multicolumn{2}{|l|}{ Benign } \\
\hline $\mathrm{BPH}$ & 53 \\
\hline BPH with Prostatitis & 21 \\
\hline $\mathrm{BPH}$ with granulomatous prostatitis & 1 \\
\hline \multicolumn{2}{|l|}{ Premalignant } \\
\hline BPH with PIN & 7 \\
\hline BPH with Prostatitis and PIN & 2 \\
\hline BPH with severe atypia, PSAP and prostatitis & 1 \\
\hline \multicolumn{2}{|l|}{ Malignant } \\
\hline Prostatic Adenocarcinoma & 15 \\
\hline Total & 100 \\
\hline
\end{tabular}

Table 2: Association of clinical features with microscopic diagnosis.

\begin{tabular}{|c|c|c|c|c|c|c|}
\hline \multirow{2}{*}{ SI.No. } & \multirow{2}{*}{ Clinical features } & \multicolumn{3}{|c|}{ Diagnosis } & \multirow{2}{*}{ Total cases } & \multirow{2}{*}{ p value\# } \\
\hline & & Benign $n(\%)$ & Premalignant $\mathrm{n}(\%)$ & Malignant n (\%) & & \\
\hline 1 & Frequency & $69(92)$ & $10(100)$ & $15(100)$ & 94 & 0.34 \\
\hline 2 & Urgency & $16(21)$ & $3(30)$ & $8(53)$ & 27 & $0.04^{*}$ \\
\hline 3 & Poor stream & $5(6.7)$ & $1(10)$ & $5(33)$ & 11 & $0.01^{*}$ \\
\hline 4 & Hesitancy & $58(77)$ & $7(70)$ & $7(46.6)$ & 72 & $0.05^{*}$ \\
\hline 5 & Acute retention & $73(97)$ & $10(100)$ & $15(100)$ & 98 & 0.71 \\
\hline 6 & Dysuria & $52(69)$ & $8(80)$ & $13(86.7)$ & 73 & 0.34 \\
\hline
\end{tabular}

Note: \# p value based on Chi-square test, * statistically significant $(p<0.05)$ 
Table 3: Microscopic findings in benign lesion $(\mathrm{N}=75)$.

\begin{tabular}{|c|l|c|c|}
\hline SI.No. & Microscopic diagnosis & Frequency & Percentage \\
\hline 1 & Nodular glandular hyperplasia (NGH) & 51 & 68 \\
\hline 2 & Corpora amylacea (CA) & 70 & 93 \\
\hline 3 & Basal cell hyperplasia (BCH) & 48 & 14.7 \\
\hline 4 & Von Brunn nests (VBN) & 11 & 92 \\
\hline 6 & Papillary infoldings (PI) & 69 & 100 \\
\hline 7 & Fibrous hyperplasia (FH) & 75 & 100 \\
\hline 8 & Muscular hyperplasia (MH) & 75 & 69.3 \\
\hline 9 & Stromal glands with atrophic glands (SFAG) & 52 & 12 \\
\hline 10 & Fibromyxoid stroma (FMS) & 9 & 76 \\
\hline 11 & Ectatic blood vessels (EBV) & 57 & 8 \\
\hline 12 & Arteriosclerosis (AS) & 6 & 32 \\
\hline 13 & Stromal edema (SE) & 24 & \\
\hline
\end{tabular}

\section{Discussion}

Prostatism and old age go hand in hand. Prostatic specimens thus constitute good percentage of workload in surgical pathology. Histopathological examination always proved to be an indispensable diagnostic tool in evaluating prostatic lesions. Hence this study was carried out to study the histopathological findings of prostatic lesions. In the present study 100 prostatic biopsies were studied. As TURP is a simple procedure with fewer complications, it is the treatment of choice for BPH and thus forms major bulk of the specimens. In our study it accounted for $91 \%$ of total cases. In a study done by Brawn et al ${ }^{[1]} 83.7 \%$ specimens were TURP among 2842 cases, our findings comparable with this study.

Prostatism is suspected in elderly with obstructive urinary symptoms. Nodules compress the urethra and cause urinary obstruction with symptoms such as increased urinary frequency, hesitancy, dribbling, and incomplete bladder emptying. In studies conducted by Guadin et $\mathrm{al}^{[2]}$ and Khan et $\mathrm{a}^{[3]}$, most common presentation was urinary retention, the finding which was in concordance with our study. In the present study, hesitancy was more common among patients with benign lesions comparable to Puttusamy et al. ${ }^{[4]}$ Frequency and dysuria were more commonly seen in patients with malignant lesions.

Prostatism increases with advancing age. In the present study, majority (47\%) of the patients were aged between 61-70 years. The incidence of benign and malignant lesions seen in this age group was in concordance with the studies conducted by Josephine et $\mathrm{a}^{\left[{ }^{[5]}\right.}$, George et al ${ }^{[6]}$ and Chandanwale et $\mathrm{al}^{\left[{ }^{[7]}\right.}$. Among patients with $\mathrm{BPH}$, the minimum age was 52 years and the maximum was 90 years. In case of patients with malignancy, minimum age was 59 years and maximum was 75 years. In our study, average age of presentation of BPH and adenocarcinoma was 68.7 and 67.3 respectively. These findings were similar to those in studies conducted by Brawn et al, ${ }^{[1]}$ Josephine et $\mathrm{al}^{\left[{ }^{5]}\right.}$ and Subathra et $\mathrm{a}^{[8]}$. In our study benign lesions constituted $75 \%$ of the total 100 cases. Of the remaining, $15 \%$ were malignant and $10 \%$ cases were pre malignant. These findings in our study were similar to those in Joshee et $\mathrm{al}^{[9]}$, Puttusamy et $\mathrm{al}^{[4]}$, Josephine et $\mathrm{al}^{[5]}$.

In $\mathrm{BPH}$, symptoms of obstruction are not necessarily related to the prostate size, but may be correlated with the proportion and histological composition of its volume. BPH is a hyperplastic process of stromal and epithelial elements forming prostate nodules. Histopathological analysis of BPH may, therefore, also have clinical and practical relevance.

In this study, the incidence of BPH was $85 \%$. Pure $\mathrm{BPH}$ was seen in 53/85 (62.6\%) cases. In other cases 32/85(37.6\%), $\mathrm{BPH}$ was associated with prostatitis, granulomatous prostatitis and premalignant lesions. Microscopically all the cases of BPH showed fibromuscular hyperplasia. Corpora amylacea, papillary infoldings and ectatic blood vessels were the next common findings. It was in concordance with the study conducted by Puttusamy et a ${ }^{[4]}$, which suggested that ectatic blood vessels may be a response to prostatic hyperplasia.

Unless it was florid, attention towards prostatic inflammation had been little by the pathologists. It is because of the undefined clinical importance. A pathologist defines prostatitis as presence of more inflammatory infiltrates in the prostatic parenchyma. In 
an urologist's aspect it is clinical syndrome characterized by genitourinary discomfort or pain. In the present study 25 cases showed features of prostatitis and the intensity of inflammation ranged from scattered to dense lymphoid nodules or follicles with germinal centre formation. Periglandular lymphocytic infiltrate is the most common pattern of inflammation with varied intensities of periglandular and stromal inflammation graded as mild, moderate and severe. It was comparable with the study conducted by Bostwik et al. ${ }^{[10]}$

\section{Conclusion}

Incidence of prostatic lesions was common in advancing ages, with highest incidence in our study was in the age group of 61-70 years. Benign lesions were more common than malignant conditions. Among the histological types of prostatic lesions, benign prostatic hyperplasia (BPH) was predominant type, followed by benign prostatic hyperplasia (BPH) with prostatitis. It is necessary to reassess periodically all prostate biopsies carefully in order to identify premalignant lesions, proliferative activity and grade of inflammation.

\section{References}

1. Brawn PN. Adenosis of the prostate: a dysplastic lesion that can be confused with prostate adenocarcinoma. Cancer. 1982 Feb 15;49(4):826-33.
2. Guadin PB, Sesterhenn IA, Wojno KJ, Mostofi FK, Epstein JI. Incidence and clinical significance of high-grade prostatic intraepithelial neoplasia in TURP specimens. Urology. 1997 Apr 1;49(4):558-63.

3. Khan M, Khan AL, Khan S, Nawaz H. Benign prostatic hyperplasia: mode of presentation and postoperative outcome. JPMA. 2005 Jan;55(1):20-3.

4. Puttusamy K, Parthiban R, Shariff S. Histopathological study of prostatic biopsies in men with prostatism. J Med Sci. 2016 Jan;2(1):12.

5. Josephine A. Clinicopathological study of prostatic biopsies. JCDR. 2014 Sep 1;8(9):FC04-06.

6. George E, Thomas S. A Histopathologic Survey Of Prostate Disease In The Sultanate Of Oman. Int J Pathol. 2004;3(2).

7. Chandanwale S, Jadhav SP, Anwekar CS, Kumar H, Buch CA, Chaudhari SU. Clinicopathological study of benign and malignant lesions of prostate. IJPBS. 2013 Jan $1 ; 3(1): 162-78$

8. Subathra K, Sangeetha N. Histopathological study of prostatic lesions and assessment with agnor index. Ind $\mathrm{J}$ Pharm Bio Sci. 2014 Apr 1;5(2):253-60.

9. Joshee A, Sharma KC. The histomorphological study of prostate lesions. IOSR-JDMS. 2015 Nov 1;14:85-9.

10. Bostwik DG, Amin MB,. Male reproductive system. In: Damjanov I, Linder J. editors. Anderson's pathology. Vol.1, 10th Ed., Missouri: Mosby; 1996.p.2197-222.

*Corresponding author:

Dr. Mourouguessine Vimal, Associate Professor, Department of Pathology, Sri Manakula Vinayagar Medical College and Hospital, Puducherry, India Phone: +91 9994083575

Email: drvimalm@gmail.com

Financial or other Competing Interests: None. 